\title{
ROLE OF THE ENDOTHELIUM IN PLACENTAL DYSFUNCTION AFTER FETAL CARDIAC BYPASS
}

V. Mohan Reddy, MD

Doff B. McElhinney, MD ${ }^{\mathrm{a}}$

Hiranya A. Rajasinghe, $\mathrm{MD}^{\mathrm{a}}$

John R. Liddicoat, MD

Karen Hendricks-Munoz, $\mathrm{MD}^{\mathrm{c}}$

Jeffrey R. Fineman, $\mathrm{MD}^{\mathrm{b}}$

Frank L. Hanley, MD
Background: Fetal cardiac bypass causes placental dysfunction, characterized by increased placental vascular resistance, decreased placental blood flow, hypoxia, and acidosis. Vasoactive factors produced by the vascular endothelium, such as nitric oxide and endothelin 1, are important regulators of placental vascular tone and may contribute to this placental dysfunction. Methods: To investigate the role of the vascular endothelium in placental dysfunction related to fetal cardiac bypass, we studied 3 groups of fetal sheep. In the first group $(n=7)$ we determined placental hemodynamic responses before and after bypass to an endothelium-dependent vasodilator (acetylcholine), an endotheliumindependent vasodilator (nitroprusside), and endothelin 1. In the second group ( $(n=8)$ a nonspecific endothelin receptor blocker (PD 145065) was administered and placental hemodynamic values were measured before and after bypass. In the third group $(n=5)$ endothelin 1 levels were measured before and after bypass. Results: Before fetal cardiac bypass exogenous endothelin 1 decreased placental blood flow by $9 \%$ and increased placental resistance by 9\%. After bypass endothelin 1 decreased placental flow by $47 \%$ and increased resistance by $106 \%$. There was also a significant attenuation of the placental vascular relaxation response to acetylcholine after bypass, whereas the response to nitroprusside was not significantly altered. In fetuses that received the PD 145065, placental vascular resistance increased significantly less than in control fetuses $(28 \%$ versus $62 \%)$. Similarly, placental blood flow decreased significantly more (from $6.3 \pm 3.1$ to $28.3 \pm 10.4 \mathrm{pg} / \mathrm{mL}$; $P=.01)$ in control fetuses than in fetuses receiving PD 145065 (33\% versus $20 \%$ ). Umbilical venous endothelin 1 levels increased significantly in fetuses exposed to fetal bypass but did not change in control fetuses. Conclusions: The basal endothelial regulatory mechanisms of placental vascular tone were deranged after fetal cardiac bypass. Endothelin receptor blockade, which substantially reduced postbypass placental dysfunction, and other interventions aimed at preserving endothelial function may be effective means of optimizing fetal outcome after cardiac bypass. (J Thorac Cardiovasc Surg 1999;117:343-51)
E or certain complex congenital heart defects, fetal car- diac surgery may yield significantly better results than can be achieved with standard methods of neonatal and infant repair. ${ }^{1}$ A prerequisite for successful fetal cardiac surgery is the ability to maintain extracorporeal

From the Division of Cardiothoracic Surgery ${ }^{\mathrm{a}}$ and Department of Pediatrics, ${ }^{\text {b }}$ University of California-San Francisco, and Department of Pediatrics, ${ }^{c}$ New York University, New York.

Supported in part by funding from the National Institutes of Health, grant RO1 HL43357.

Read at the Seventy-eighth Annual Meeting of The American Association for Thoracic Surgery, Boston, Mass, May 3-6, 1998.

Received for publication May 8, 1998; revisions requested June 19, fetal circulatory support (fetal cardiac bypass) safely and reliably. Previous studies have shown that the major hindrance to fetal cardiac bypass is peribypass placental dysfunction, which is characterized by elevated placental vascular resistance (PVR), decreased placental blood

1998; revisions received Sept 30, 1998; accepted for publication Oct 7, 1998

Address for reprints: V. Mohan Reddy, MD, Division of Cardiothoracic Surgery, 505 Parnassus Ave, M593 San Francisco, CA 94143-0118.

Copyright (C) 1999 by Mosby, Inc.

$0022-5223 / 99 \$ 8.00+0 \quad \mathbf{1 2 / 6 / 9 5 0 1 6}$ 
flow (PBF), acidosis, hypoxia, and hypercarbia. ${ }^{2-4} \mathrm{~A}$ number of mechanisms of bypass-related placental dysfunction have been found, and various interventions have been shown to improve hemodynamics and gas exchange during and after fetal cardiac bypass. ${ }^{2-6}$

One potentially important aspect of fetoplacental circulatory physiology and bypass-related placental dysfunction that has not been studied extensively is the role of placental endothelial function. The placental vasculature is thought to be maximally dilated in the basal state. $^{7}$ Recent evidence indicates that nitric oxide ${ }^{8-10}$ and endothelin 1 (ET-1) $)^{11-13}$ are important regulators of placental vascular tone. Endothelial factors such as these may therefore have a role in the placental dysfunction that has been observed to occur during and after fetal cardiac bypass. ${ }^{6}$ In this study we performed a series of experiments to address this dimension of placental pathophysiology after fetal cardiac bypass.

\section{Methods}

To investigate the role of the vascular endothelium in placental dysfunction related to fetal cardiac bypass, we studied 3 groups of fetal sheep. In the first (group $1, n=7$ ), we investigated the effect of bypass on placental endothelial function by comparing hemodynamic responses before and after fetal bypass to an endothelium-dependent vasodilator (acetylcholine), an endothelium-independent vasodilator (sodium nitroprusside), and ET-1, a vasoactive polypeptide produced by the endothelium. In the second group (group 2, n = 8) the role of endogenous ET-1 in bypass-related placental dysfunction was assessed by comparing placental hemodynamics before and after bypass between 8 fetuses administered an ET-1 receptor blocker (PD 145065) and 5 control fetuses that did not receive PD 145065. In the third group (group 3, n = 5) the aim was to determine whether the circulating level of endogenous ET-1 was affected by fetal cardiac bypass. No medications were given and umbilical venous ET-1 levels were measured before and after fetal cardiac bypass. ET-1 levels and hemodynamics were also measured in 4 control fetuses that had instruments placed and were exposed in an identical fashion but were not placed on bypass.

Surgical preparation and fetal cardiac bypass. Anesthesia, operation, and fetal cardiac bypass were performed as previously described at 118 to 122 days' gestation in singleton or twin fetuses carried by mixed-breed pregnant ewes. ${ }^{14}$ After anesthesia and exposure of the fetus, a fetal flank incision was made to allow placement of a number $6 \mathrm{~S}$ series ultrasonic perivascular flow probe (Transonic Systems Inc, Ithaca, NY) around the common umbilical artery for continuous monitoring of PBF. A 20-gauge arterial catheter was placed into the descending aorta 1 inch proximal to the common umbilical artery and secured. The flow probe and arterial line were brought outside and the fetal incision and hysterotomy were closed. The fetal chest was exposed through a second hysterotomy. Fetal electrocardiographic leads were placed to monitor the heart rate. A jugular venous line was placed to administer intravenous fluids and monitor fetal central venous pressure. Fetal temperature was monitored with a temperature probe placed in the fetal peritoneal cavity, and temperatures were maintained above $36^{\circ} \mathrm{C}$ at all times by wrapping the uterus in a thermal heating blanket $\left(40^{\circ} \mathrm{C}\right)$ and intermittently pouring warm saline solution over the fetus and uterus.

Midline fetal sternotomy and pericardiotomy were performed and the heart was exposed. The main pulmonary artery and the ascending aorta were dissected. and perivascular flow probes were placed around the main pulmonary artery (number $8 \mathrm{~S}$ probe) and the aorta (number $6 \mathrm{~S}$ probe) for continuous monitoring of the combined ventricular output.

The fetus underwent anticoagulation with 300 units $/ \mathrm{kg}$ heparin administered through the superior vena cava. The right atrium was cannulated through the superior vena cava with a $16 \mathrm{~F}$ angled-tip venous cannula, and the bypass circuit was filled with fetal blood and cleared of air. The main pulmonary artery was cannulated with a $12 \mathrm{~F}$ arterial cannula, which was then filled with fetal blood and cleared of air. The arterial and venous cannulas were connected with 0.25 -inch polyvinyl tubing to a previously described bypass circuit, ${ }^{14}$ which uses an in-line axial flow pump (Hemopump, modified model HP24 sternotomy pump; Medtronic Inc, Grand Rapids, Mich) and an in-line flow probe. Bypass was initiated. During bypass the flow probe was removed from the main pulmonary artery because flow in this vessel was equal to pump flow. Backflow from the main pulmonary artery into the ventricle and backflow from the ventricle into the main pulmonary artery were prevented by crossclamping the artery just above the pulmonary valve, proximal to the cannulation site.

Because of the need for high flows when the placenta is incorporated into the circulation for oxygenation, pump flows were maintained at the maximum achievable flow in each animal (generally about $250-300 \mathrm{~mL} \cdot \mathrm{kg}^{-1} \cdot \mathrm{min}^{-1}$ ). Pump flows were monitored continuously with the in-line flow probe. After 30 minutes of bypass the cannulas were removed, the condition of the fetus was allowed to stabilize for 15 minutes, and the study was resumed. After completion of the study the ewes and fetuses were killed by an overdose of intravenous pentobarbital. The dead fetuses were delivered and an autopsy was performed to confirm the positions of all vascular catheters. The amniotic fluid was dried and the fetuses were weighed.

All animals received humane care in compliance with the "Principles of Laboratory Animal Care" formulated by the National Society of Medical Research and the "Guide for the Care and Use of Laboratory Animals" prepared by the Institute of Laboratory Animal Resources and published by the National Institutes of Health (NIH Publication No. 86-23, revised 1985). The experimental protocol was approved by the Committee for Animal Care at the University of California, San Francisco.

Experimental protocol

Group 1. Acetylcholine chloride (Iolab Corp, Claremont, Calif) was diluted in sterile $0.9 \%$ saline solution. Sodium 
nitroprusside (Abbott Laboratories, Chicago, Ill) was diluted in 5\% dextrose in water. ET-1 (0.5 mg, MW 2491.1; Peptides International, Inc, Louisville, Ky) was resuspended in $10 \mathrm{~mL}$ sterile water and stored at $-20^{\circ} \mathrm{C}$. All solutions were prepared on the day of the study.

After exposure of and placement of instrumentation in the fetuses but before cardiac bypass, the following pharmacologic interventions were performed, in random order: acetylcholine $(1 \mu \mathrm{g} / \mathrm{kg}$ bolus $)$, nitroprusside $\left(1 \mu \mathrm{g} \cdot \mathrm{kg}^{-1} \cdot \mathrm{min}^{-1}\right.$ infusion), and ET-1 (125 ng/kg bolus). Between each intervention hemodynamic and blood gas variables were monitored, and the next intervention was performed only after all variables had returned to baseline and stabilized. After fetal cardiac bypass the conditions of fetuses were allowed to stabilize for at least 15 minutes. At this point the aforementioned pharmacologic interventions were performed again, in random order.

Group 2. After placement of instrumentation in the fetus but before initiation of fetal cardiac bypass, an infusion of PD 145065 , a nonselective endothelin receptor blocker $(50 \mu \mathrm{g}$. $\mathrm{kg}^{-1} \cdot \mathrm{min}^{-1}$, synthesized by the Medicinal Chemistry Department; Parke-Davis Pharmaceutical Research, Ann Arbor, Mich), was started. ${ }^{15}$ Thirty minutes was allowed to elapse and fetoplacental hemodynamics before bypass were recorded; after that, bypass was initiated. The PD 145065 infusion was continued during the entire period of fetal cardiac bypass and throughout the postbypass study period. The dose of PD 145065 was chosen on the basis of a previous study, which showed that a 30-minute infusion completely blocked the vasoconstrictive effects of exogenous ET- $1 .{ }^{16}$ After discontinuation of bypass the conditions of fetuses were allowed to stabilize, and postbypass hemodynamic measurements were recorded 30 minutes after bypass. To document that PD 145065 had completely antagonized ET-1, a bolus of exogenous ET-1 was administered at 60 minutes after bypass in twice the dose as that used in group $1(250 \mathrm{ng} / \mathrm{kg})$ and the hemodynamic response was recorded. In control animals the same protocol was used, but crystalloid solution (Normosol, $\mathrm{pH}$ 7.4; Abbott Laboratories) was infused instead of PD 145065 , at the same rate.

Group 3. In this group no medications were given and plasma ET-1 levels were measured before and 15 minutes after bypass. ET-1 levels were measured from $4 \mathrm{~mL}$ umbilical venous blood according to a previously described assay. ${ }^{17}$ The blood was placed in iced polypropylene tubes containing $100 \mu \mathrm{L}$ ethylenediaminetetraacetic acid and $330 \mu \mathrm{L}$ aprotinin and then immediately centrifuged at $4000 \mathrm{~g}$ for 20 minutes. The plasma was treated with an equal volume of $0.1 \%$ trifluoroacetic acid and stored at $-70^{\circ} \mathrm{C}$. The acidified supernatant was centrifuged at $1000 \mathrm{~g}$ for 20 minutes and loaded on a $3 \times$ 18 C18 Sep-Pak column (Peninsula Laboratories, Belmont, Calif) equilibrated with $0.1 \%$ trifluoroacetic acid. The adsorbed material was eluted with $3 \mathrm{~mL} 0.1 \%$ trifluoroacetic acid and $60 \%$ acetonitrile. The eluant was dried and stored at $-70^{\circ} \mathrm{C}$ or assayed immediately for immunoreactive ET-1. ET1 standard, ET-1 labeled with iodine 125, antiendothelin antibody, and secondary antibody were purchased from
Peninsula Laboratories. Cross-reactivities for measured human and bovine ET-1 antiserum were $100 \%$ for human ET1, 7\% for human endothelins 2 and 3, and $0 \%$ for bovine endothelins 2 and 3. Each sample was assayed twice, and the average of the 2 runs was recorded for analysis.

Hemodynamic monitoring. Systemic arterial pressure (SAP) and central venous pressure were measured with Statham P23Db pressure transducers (Statham Instruments, Hato Rey, Puerto Rico). Mean pressures were obtained by means of electrical integration. Heart rate was measured with a cardiotachometer triggered by the phasic SAP pulse wave. Flows were measured with ultrasonic flowmeters (Transonic Systems). All hemodynamic variables were recorded continuously on a Gould multichannel electrostatic recorder (model TA11; Gould Inc, Cleveland, Ohio). Fetal and maternal arterial blood gas and $\mathrm{pH}$ values were measured on a Corning $158 \mathrm{pH} / \mathrm{blood}$ gas analyzer (Corning Medical and Scientific, Medfield, Mass).

Maternal and fetal heart rates, central venous pressure, and SAP were recorded continuously during the entire study. Fetal combined ventricular output and PBF were also monitored continuously. In group 1 baseline hemodynamic values were recorded before each intervention (preintervention values), and postintervention values were recorded at the point of maximum effect, usually within 2 minutes of drug administration. In group 2 prebypass hemodynamic values were recorded after 30 minutes of PD 145065 infusion. Maternal blood gas values were measured every 30 minutes to ensure adequate ventilation. Fetal blood gas values were measured after placement of instrumentation, immediately before bypass, every 15 minutes during bypass, and every 15 minutes after bypass until completion of the study. At each of these points hemodynamic data were also recorded.

Data analysis. PVR and systemic vascular resistance (SVR) were calculated from standard formulas relating resistance to pressure and flow (the Ohm law). Combined ventricular output was calculated as the sum of the ascending aortic and main pulmonary artery (or pump) flows. Systemic blood flow (SBF) was estimated as the difference between combined ventricular output and PBF. Data were expressed as mean \pm SD. SPSS version 6.0 (SPSS Inc, Chicago Ill) was used for all statistical analyses. Differences between groups were assessed by general factorial analysis of variance. Paired 2-tailed $t$ tests were used to assess the significance of changes in hemodynamic variables (with respect to baseline levels before administration) after acetylcholine, sodium nitroprusside, and ET-1 were given, both before and after bypass. The significance of differences between prebypass and postbypass responses (mean percentages change) to administration of acetylcholine, nitroprusside, and ET-1 was also examined by paired 2-tailed $t$ test analysis.

\section{Results}

Group 1. Results of prebypass and postbypass interventions are summarized in Table I and also described. There were no significant differences in baseline SAP, 
Table I. Hemodynamic effects of acetylcholine, nitroprusside, and ET-1 administration before and after cardiac bypass in group 1 fetuses $(n=7)$

\begin{tabular}{|c|c|c|c|c|c|}
\hline Intervention and timing & $\begin{array}{c}S A P \\
(m m \mathrm{Hg})\end{array}$ & $\begin{array}{c}P B F \\
\left(m L \cdot m i n^{-1} \cdot k g^{-1}\right)\end{array}$ & $\begin{array}{c}S B F \\
\left(\mathrm{~mL} \cdot \mathrm{min}^{-1} \cdot \mathrm{kg}^{-1}\right)\end{array}$ & $\begin{array}{c}P V R \\
\left(m m H^{-1} \cdot \mathrm{mL}^{-1}\right. \\
\left.\mathrm{min}^{-1} \cdot \mathrm{kg}^{-1}\right)\end{array}$ & $\begin{array}{c}\text { SVR } \\
\left(\mathrm{mm} \mathrm{Hg} \cdot \mathrm{mL}^{-1}\right. \\
\left.\mathrm{min}^{-1} \cdot \mathrm{kg}^{-1}\right)\end{array}$ \\
\hline \multicolumn{6}{|c|}{ Acetylcholine, before bypass } \\
\hline Before acetylcholine & $59.4 \pm 7.9$ & $131.0 \pm 27.5$ & $129.3 \pm 66.9$ & $0.48 \pm 0.14$ & $0.56 \pm 0.23$ \\
\hline After acetylcholine & $52.9 \pm 6.2 \ddagger$ & $145.7 \pm 25.8 \ddagger$ & $105.6 \pm 60.4 \$$ & $0.37 \pm 0.09 \dagger$ & $0.66 \pm 0.34$ \\
\hline \multicolumn{6}{|l|}{ Acetylcholine, after bypass } \\
\hline Before acetylcholine & $60.6 \pm 2.8$ & $79.4 \pm 22.7$ & $137.9 \pm 67.0$ & $0.85 \pm 0.39$ & $0.56 \pm 0.32$ \\
\hline After acetylcholine & $55.7 \pm 3.9 \ddagger$ & $84.0 \pm 22.2 \dagger$ & $134.4 \pm 64.7$ & $0.73 \pm 0.31 \dagger$ & $0.52 \pm 0.29$ \\
\hline \multicolumn{6}{|l|}{$\begin{array}{l}\text { Sodium nitroprusside, } \\
\text { before bypass }\end{array}$} \\
\hline Before nitroprusside & $56.9 \pm 3.4$ & $129.9 \pm 32.0$ & $117.9 \pm 79.6$ & $0.46 \pm 0.13$ & $0.67 \pm 0.41$ \\
\hline After nitroprusside & $49.7 \pm 2.9 \ddagger$ & $123.6 \pm 32.3 \dagger$ & $99.1 \pm 69.7$ \$ & $0.43 \pm 0.12 \dagger$ & $0.72 \pm 0.44^{*}$ \\
\hline \multicolumn{6}{|l|}{$\begin{array}{l}\text { Sodium nitroprusside, } \\
\text { after bypass }\end{array}$} \\
\hline Before nitroprusside & $59.1 \pm 4.7$ & $70.1 \pm 18.7$ & $147.0 \pm 70.9$ & $0.92 \pm 0.36$ & $0.49 \pm 0.24$ \\
\hline After nitroprusside & $51.4 \pm 4.6 \ddagger$ & $67.2 \pm 19.4$ & $135.5 \pm 64.1^{*}$ & $0.84 \pm 0.32 *$ & $0.45 \pm 0.19$ \\
\hline \multicolumn{6}{|l|}{ ET-1, before bypass } \\
\hline Before ET-1 & $55.9 \pm 3.9$ & $133.4 \pm 39.1$ & $112.6 \pm 70.7$ & $0.46 \pm 0.18$ & $0.77 \pm 0.62$ \\
\hline After ET-1 & $55.7 \pm 4.8$ & $121.8 \pm 36.7 \dagger$ & $118.7 \pm 70.7 \$$ & $0.51 \pm 0.21 \dagger$ & $0.70 \pm 0.55^{*}$ \\
\hline \multicolumn{6}{|l|}{ ET-1, after bypass } \\
\hline Before ET-1 & $57.4 \pm 4.1$ & $73.0 \pm 18.1$ & $145.5 \pm 67.3$ & $0.86 \pm 0.34$ & $0.47 \pm 0.20$ \\
\hline After ET-1 & $59.4 \pm 2.8^{*}$ & $38.4 \pm 13.1 \$$ & $169.4 \pm 72.6 \dagger$ & $1.73 \pm 0.67 末$ & $0.40 \pm 0.14^{*}$ \\
\hline
\end{tabular}

Values are mean \pm SD.

$* P \leq .001$ relative to preintervention values.

$\dagger P \leq .01$ relative to preintervention values.

$\ddagger P \leq .05$ relative to preintervention values.

combined ventricular output, PBF, SBF, PVR, or SVR before administration of the 3 pharmacologic agents, both before and after bypass.

Acetylcholine. In response to acetylcholine administration SAP decreased significantly before and after bypass. As depicted in Fig 1, PBF increased with both prebypass and postbypass acetylcholine administration, although the increase was attenuated after bypass ( $7 \%$ versus $12 \%$ before bypass, $P=.04)$. SBF decreased significantly $(P=.0005)$ before bypass but not after bypass. The difference between prebypass and postbypass SBF responses to acetylcholine was significant $(P$ $=.001)$. PVR decreased significantly after prebypass and postbypass administration of acetylcholine, but the PVR decrease was significantly greater before bypass than after bypass (Fig 1). Alhough SVR did not change significantly before or after bypass, the difference between prebypass and postbypass SVR responses to acetylcholine was significant (18\% increase prebypass versus $7 \%$ decrease postbypass; $P=.006$ ).

Sodium nitroprusside. SAP decreased significantly after nitroprusside administration both before and after bypass. Nitroprusside administration led to a significant drop in PBF before bypass but not after bypass (Fig 1).
The difference between prebypass and postbypass PBF responses to nitroprusside was not significant. SBF fell significantly after both prebypass and postbypass nitroprusside administration, but the response was significantly greater before bypass than after bypass $(P=.01)$. As shown in Fig 1, PVR decreased significantly after prebypass and postbypass nitroprusside administration, but the PVR responses to nitroprusside before and after bypass did not differ significantly. Calculated SVR rose significantly (although by $<10 \%$ ) in response to prebypass nitroprusside administration but not postbypass nitroprusside administration. The difference between prebypass and postbypass changes after nitroprusside administration was significant $(P=.01)$.

Endothelin 1. In response to ET-1 administration there was a small but significant increase in SAP after bypass but not before bypass. SBF increased significantly before and after bypass, and the postbypass increase was significantly greater than the prebypass response $(P=.04)$. PBF decreased significantly in response to ET-1 administration before and after bypass, but the response was significantly greater after bypass than before bypass (Fig 1). PVR increased significantly after prebypass and postbypass ET- 1 admin- 

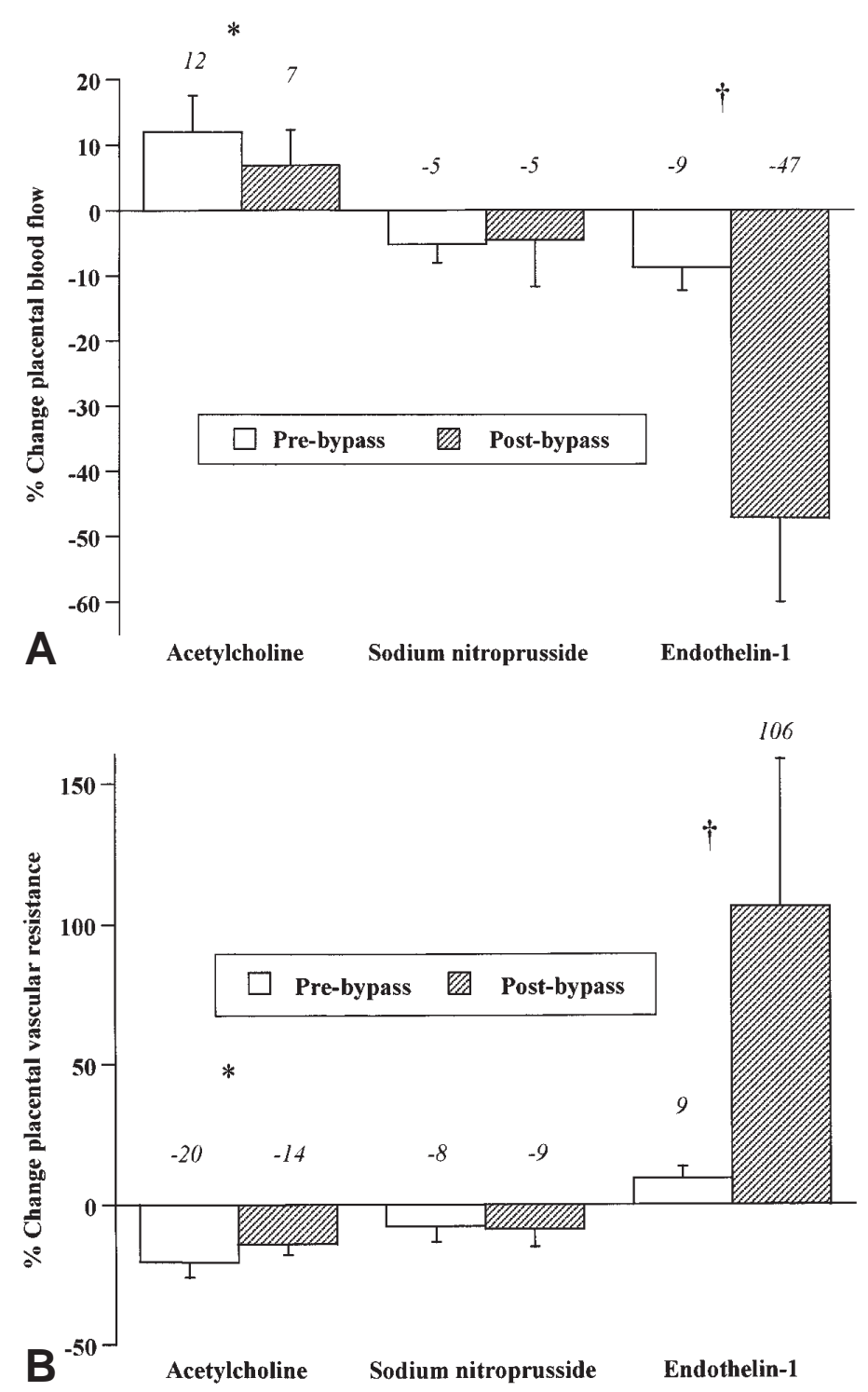

Fig 1. Mean \pm SD percentage change in indexed placental blood flow (A) and indexed PVR (B) after acetylcholine, sodium nitroprusside, and ET-1 administration before and after fetal cardiac bypass $(\mathrm{n}=7)$. Mean values are displayed above the columns. Asterisk represents $P \leq .05$ and dagger represents $P \leq .01$ for paired 2-tailed $t$ test comparisons between prebypass and postbypass mean percentage changes in PBF or PVR after administration of acetylcholine or ET-1. Error bars represent SD.

istration (Fig 1), but the postbypass response was markedly more pronounced $(P=.003)$. ET- 1 administration caused a significant decrease in SVR both before and after bypass.

Group 2. In the group of eight fetuses that received the ET-1 blocker PD 145065, PVR increased from 0.32 $\pm 0.03 \mathrm{~mm} \mathrm{Hg} \cdot \mathrm{mL}^{-1} \cdot \mathrm{min}^{-1} \cdot \mathrm{kg}^{-1}$ before bypass to $0.41 \pm 0.07 \mathrm{~mm} \mathrm{Hg} \cdot \mathrm{mL}^{-1} \cdot \mathrm{min}^{-1} \cdot \mathrm{kg}^{-1}$ after bypass, which was significantly less than in control animals $\left(0.31 \pm 0.04 \mathrm{~mm} \mathrm{Hg} \cdot \mathrm{mL}^{-1} \cdot \mathrm{min}^{-1} \cdot \mathrm{kg}^{-1}\right.$ before bypass and $0.51 \pm 0.14 \mathrm{~mm} \mathrm{Hg} \cdot \mathrm{mL}^{-1} \cdot \mathrm{min}^{-1} \cdot \mathrm{kg}^{-1}$ after bypass, $P=.01)$. Similarly, PBF decreased significantly more in control animals (from $184 \pm 22 \mathrm{~mL} \cdot \mathrm{min}^{-1}$ . $\mathrm{kg}^{-1}$ to $\left.119 \pm 20 \mathrm{~mL} \cdot \mathrm{min}^{-1} \cdot \mathrm{kg}^{-1}\right)$ than in fetuses receiving ET-1 receptor blocker (from $178 \pm 28 \mathrm{~mL}$. $\mathrm{min}^{-1} \cdot \mathrm{kg}^{-1}$ to $146 \pm 18 \mathrm{~mL} / \mathrm{min} / \mathrm{kg} \mathrm{mL} \cdot \mathrm{min}^{-1} \cdot \mathrm{kg}^{-1}$, $P=.02$ ). These results are depicted in Fig 2. In response to the bolus of ET-1 administered 60 minutes 

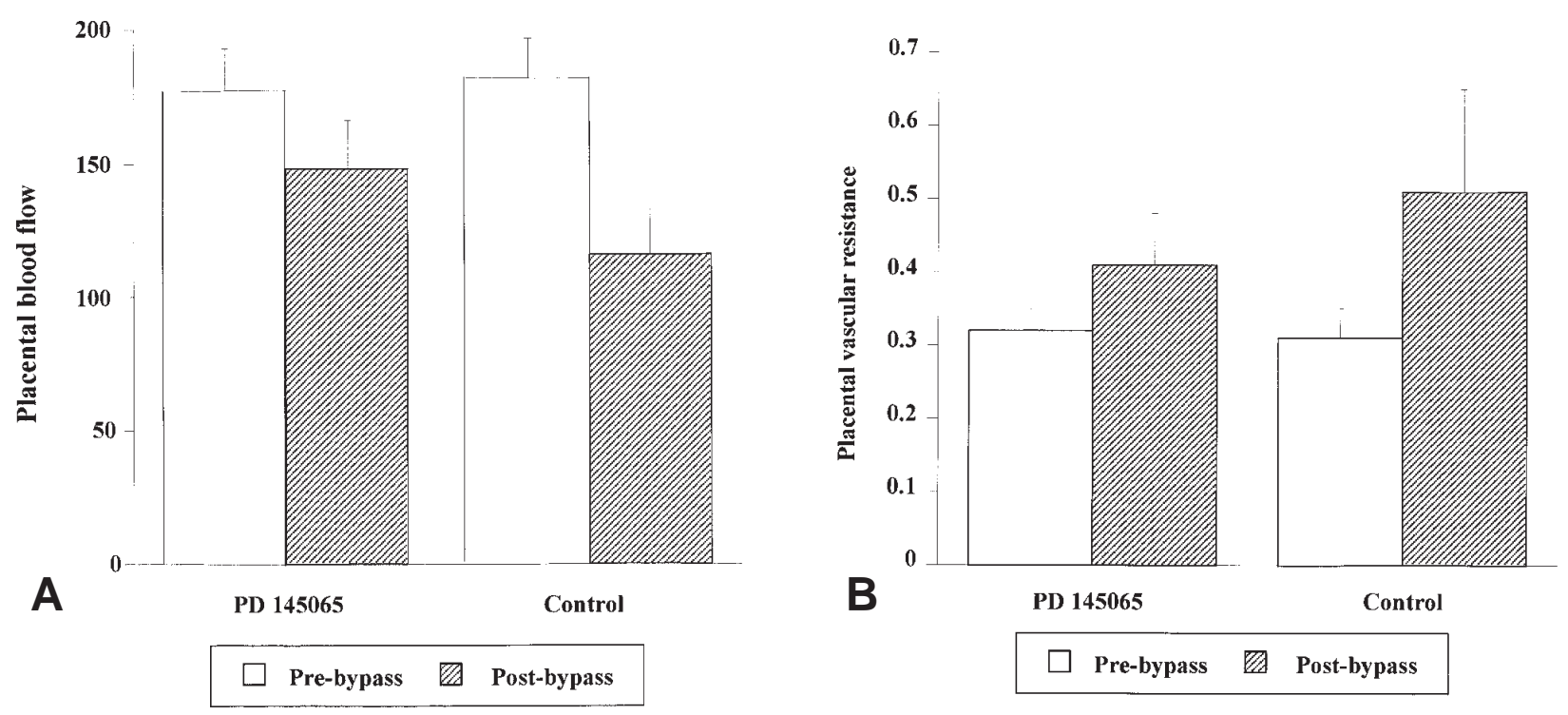

Fig 2. Mean \pm SD PBF (A) and PVR (B) before and after bypass in group 2 fetuses that underwent cardiac bypass with the ET-1 receptor blocker PD $145065(\mathrm{n}=8)$ and in fetuses that underwent bypass without PD 145065 (Control, $\mathrm{n}=5$ ). PBF is given in milliliters per minute per kilogram and PVR is given in millimeters of mercury per milliliter per minute per kilogram.

after bypass, no changes in any of the hemodynamic variables monitored were seen in fetuses that received PD 145065, whereas those that had not received the ET-1 blocker had significantly decreased PBF (from $112 \pm 23 \mathrm{~mL} \cdot \mathrm{min}^{-1} \cdot \mathrm{kg}^{-1}$ immediately before administration of ET-1 to $23 \pm 11 \mathrm{~mL} \cdot \mathrm{min}^{-1} \cdot \mathrm{kg}^{-1} 10 \mathrm{~min}$ utes afterward, $P<.001$ ) and increased PVR (from 0.55 $\pm 0.03 \mathrm{~mm} \mathrm{Hg} \cdot \mathrm{mL}^{-1} \cdot \mathrm{min}^{-1} \cdot \mathrm{kg}^{-1}$ to $3.16 \pm 1.62 \mathrm{~mm}$ $\left.\mathrm{Hg} \cdot \mathrm{mL}^{-1} \cdot \mathrm{min}^{-1} \cdot \mathrm{kg}^{-1}, P<.001\right)$. This difference between the 2 groups confirms the endothelin receptor blockade in the fetuses that received PD 145065.

Group 3. Plasma ET-1 level increased significantly in fetuses placed on cardiac bypass but did not change in control animals (Table II and Fig 3). PBF decreased significantly and PVR increased significantly in the 5 fetuses exposed to bypass (Table II). There were no changes in hemodynamics or serum ET-1 levels in the 4 control fetuses.

\section{Discussion}

Fetal cardiac surgery may offer a means of repairing certain congenital heart defects with better results than can be achieved after birth. ${ }^{1}$ To gain surgical access to the fetal heart, it is necessary to develop a safe and effective method of fetal cardiac bypass for extracorporeal circulatory support. Studies to date have discovered that fetal cardiac bypass is complicated by placental dysfunction..$^{2-4}$ As with the systemic inflammatory response syndrome that occurs after cardiopulmonary bypass in infants and adults, ${ }^{18}$ a number of factors have been implicated in fetal cardiac bypass-related placental dysfunction, including the fetal stress response, eicosanoid elaboration, extracorporeal surfaces, and nonpulsatile flow. ${ }^{2-5,14}$ Cardiopulmonary bypass in pediatric patients has been shown to result in elevated levels of circulating ET-1, and there is evidence that cardiopulmonary bypass causes endothelial damage. ${ }^{20}$ However, there are no reported studies of the role of endothelial factors in peribypass placental dysfunction or of the placental endothelial response to fetal cardiac bypass.

It is well known that endothelium-derived relaxing factors, such as nitric oxide, are important regulators of placental vascular tone. ${ }^{8-10}$ Chaudhuri and associates ${ }^{8}$ demonstrated an endothelium-dependent release of nitric oxide from human umbilical veins. Others have shown increased PVR and decreased PBF after selective inhibition of nitric oxide synthesis with $N^{\omega}$-nitro-Larginine in both fetal lambs and isolated human placental cotyledons. ${ }^{9,10}$ In this study we indirectly assessed the effect of fetal cardiac bypass on endothelial nitric oxide production by comparing prebypass and postbypass vasodilation of the placental vascular bed by endothelium-dependent and independent mechanisms. Acetylcholine, which increases endothelial nitric oxide production by means of receptor-mediated 
Table II. Placental hemodynamics and ET-1 levels before and after fetal cardiac bypass

\begin{tabular}{|c|c|c|}
\hline & $\begin{array}{l}\text { Bypass } \\
(n=5)\end{array}$ & $\begin{array}{l}\text { Control }^{*} \\
(n=4)\end{array}$ \\
\hline \multicolumn{3}{|l|}{$\begin{array}{l}\text { Umbilical venous serum ET-1 } \\
(\mathrm{pg} / \mathrm{mL})\end{array}$} \\
\hline Before bypass & $6.3 \pm 3.1$ & $3.8 \pm 2.7$ \\
\hline After bypass or waiting & $28.3 \pm 10.4 \dagger$ & $5.4 \pm 1.1$ \\
\hline \multicolumn{3}{|l|}{$\begin{array}{l}\text { Placental blood flow } \\
\left(\mathrm{mL} \cdot \mathrm{min}^{-1} \cdot \mathrm{kg}^{-1}\right)\end{array}$} \\
\hline Before bypass & $170 \pm 28$ & $155 \pm 14$ \\
\hline After bypass or waiting & $127 \pm 36 \dagger$ & $146 \pm 13 \dagger$ \\
\hline $\begin{array}{l}\text { Change from before to after } \\
\text { bypass }(\%)\end{array}$ & $-26 \pm 11 \ddagger$ & $-6 \pm 3$ \\
\hline \multicolumn{3}{|l|}{$\begin{array}{l}\text { PVR }\left(\mathrm{mm} \mathrm{Hg} \cdot \mathrm{mL}^{-1}\right. \\
\left.\min ^{-1} \cdot \mathrm{kg}^{-1}\right)\end{array}$} \\
\hline Before bypass & $0.33 \pm 0.05$ & $0.39 \pm 0.10$ \\
\hline After bypass or waiting & $0.44 \pm 0.01 \dagger$ & $0.40 \pm 0.10$ \\
\hline $\begin{array}{l}\text { Change from before to after } \\
\text { bypass }(\%)\end{array}$ & $34 \pm 19 \ddagger$ & $2 \pm 2$ \\
\hline
\end{tabular}

Data are expressed as mean $\pm \mathrm{SD}$.

*Control animals were not placed on bypass but were exposed similar to bypass fetuses for 30 minutes.

$\dagger P \leq .01$ versus values before bypass.

$\ddagger P \leq .001$ versus control values.

stimulation of nitric oxide synthase, was used as the endothelium-dependent vasodilator. Sodium nitroprusside, which exerts its vasodilatory effect by acting as a nitric oxide donor, was used as the endothelium-independent vasodilator. Because the nitric oxide contributed by these 2 mechanisms acts through a final common pathway, a comparison of the vasoactive effects of acetylcholine and nitroprusside may be used to evaluate the ability of the endothelium to produce nitric oxide in response to normal stimulatory signals. Our results demonstrate a selective impairment in endothelium-dependent vasodilation. After bypass acetylcholine administration induced significantly smaller increase in PBF (7\% vs $12 \%, P<.05)$ and decrease in PVR $(14 \%$ vs $20 \%, P<.05)$ than it did before bypass. In contrast, bypass had no effect on the PBF or PVR response to nitroprusside.

ET-1 is also known to be an important regulator of placental vascular tone. ${ }^{11-13}$ Several groups have demonstrated a dose-dependent increase in PVR in response to ET-1 administration, a reaction that could be blocked by inhibition of endothelin-converting enzyme with phosphoramidon. ${ }^{11,12}$ In examining the effects of ET- 1 on placental vascular tone, it is important to consider its complex vasoactive properties. The hemodynamic effects of ET- 1 are mediated by 2 different subtypes of endothelin receptors, $\mathrm{ET}_{\mathrm{A}}$ and $\mathrm{ET}_{\mathrm{B}}{ }^{21}$

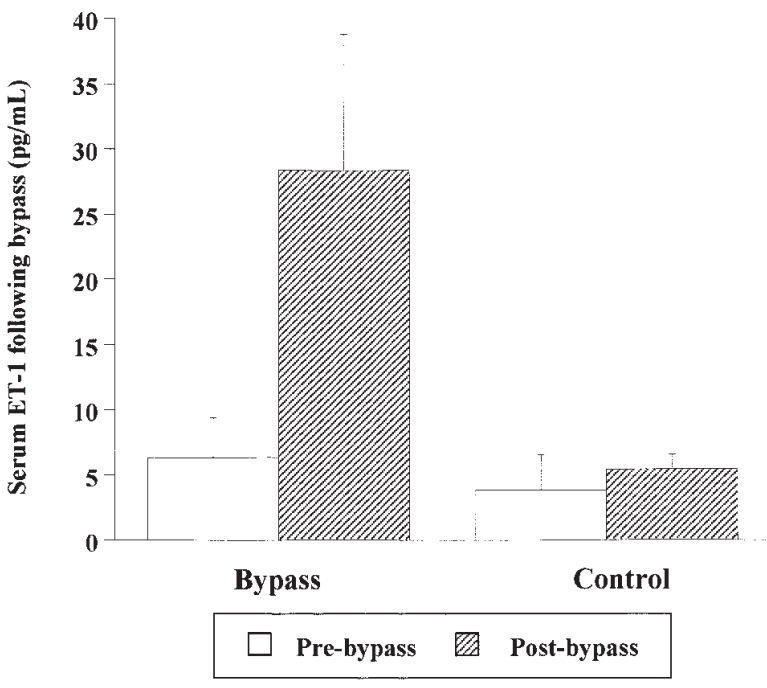

Fig 3. Mean \pm SD umbilical venous serum ET-1 (in picograms per milliliter) in fetuses that were placed on cardiac bypass (Bypass, $\mathrm{n}=5$ ) and control fetuses that were not (Control, $\mathrm{n}=4)$.

$\mathrm{ET}_{\mathrm{A}}$ receptors and a subpopulation of $\mathrm{ET}_{\mathrm{B}}$ receptors mediate vasoconstriction and are located on vascular smooth muscle cells, whereas another subpopulation of $\mathrm{ET}_{\mathrm{B}}$ receptors mediates vasodilation and is located on vascular endothelial cells. ${ }^{21}$ Both $\mathrm{ET}_{\mathrm{A}}$ and $\mathrm{ET}_{\mathrm{B}}$ receptors are present in the placenta. ${ }^{22}$ In this study the most dramatic difference between prebypass and postbypass endothelial function was seen with the administration of ET-1. Before bypass ET-1 decreased PBF by $9 \%$ and increased PVR by 9\%. After bypass, however, ET-1 administration resulted in a significantly greater decrease in PBF (47\%; $P=.0005)$ and a significantly greater rise in PVR $(106 \% ; P=.001)$. Nonspecific endothelin receptor blockade blunted the hemodynamic response to bypass to a significant degree, and absence of the PVR and PBF response to exogenous ET-1 administration in these fetuses confirmed the endothelin receptor antagonism. Moreover, there was significant elevation of umbilical venous serum ET-1 level after bypass in group 3 fetuses. Taken together, these results provide strong evidence in support of a role for ET-1 in placental dysfunction after fetal cardiac bypass.

Physiologic antagonism between nitric oxide and ET1 has been shown in many regional circulations. ${ }^{23}$ Our data suggest that the increase in PVR after fetal bypass may be multifactorial, related to a combination of decreased nitric oxide production by the endothelium, increased circulating levels of ET-1 acting on $\mathrm{ET}_{\mathrm{A}}$ 
receptors, and decreased vasodilation through endothelial $\mathrm{ET}_{\mathrm{B}}$ receptors. Endothelial injury could account for all these changes; however, more investigation is necessary to determine the specific mechanisms of endothelial dysfunction after fetal cardiac bypass. As Champsaur and colleagues ${ }^{6}$ showed, the addition of pulsatile flow to the fetal bypass protocol may stimulate the release of nitric oxide and the resulting vasodilatory response, helping to preserve placental hemodynamics during and after bypass. If the endothelial system can be effectively and safely modulated with specific inhibitors (unlike the nonspecific endothelin receptor blocker used in this study) or other means, such as pulsatile flow or minimization of the humoral response to the bypass circuit, ${ }^{14}$ it may be possible to significantly improve placental function and fetal outcome after cardiac bypass. In addition, it will be important to elucidate the relationships among the endothelial, eicosanoid, cytokine, and adrenergic systems in producing the comprehensive hemodynamic response to fetal bypass. Previous studies documented that inhibition of the cyclo-oxygenase cascade with indomethacin and inhibition of the fetal stress response with glucocorticoids can lead to improved hemodynamics and survival after fetal bypass. ${ }^{2,4}$ These systems almost certainly interact with the process of endothelium-mediated placental dysfunction studied in this set of experiments. The nature of these relationships and the optimal means of mediating the impairment in placental dysfunction require further study.

We acknowledge the technical help provided by Roger Chang and Rene Garrets. We also acknowledge Walid K. Abol Hosn and Mike Wright of Johnson and Johnson Interventional systems, Rancho Cordova, Calif, for their technical help and support.

\section{REFERENCES}

1. Hanley FL. Fetal cardiac surgery. Adv Card Surg 1994;5:47-74.

2. Sabik JF, Assad RS, Hanley FL. Prostaglandin synthesis inhibition prevents placental dysfunction after fetal cardiac bypass. J Thorac Cardiovasc Surg 1994;103:733-42.

3. Sabik JF, Heinemann MK, Assad RS, Hanley FL. High steroids prevent placental dysfunction after fetal cardiac bypass. J Thorac Cardiovase Surg 1994;107:116-25.

4. Fenton KN, Heinemann MK, Hickey PR, Klautz RJ, Liddicoat JR, Hanley FL. Inhibition of fetal stress response improves cardiac output and gas exchange after fetal cardiac bypass. J Thorac Cardiovasc Surg 1994;107:1416-22.

5. Champsaur G, Parisot P, Martinot S, Ninet J, Robin J, Ovize M, et al. Pulsatility improves hemodynamics during fetal bypass: experimental study of pulsatile versus steady flow. Circulation 1994;90(5 Pt 2):II47-50.

6. Champsaur G, Vedrinne C, Martinot S, Trone F, Robin J, Ninet J, et al. Flow-induced release of endothelium-derived relaxing factor during pulsatile bypass: experimental study in the fetal lamb. J Thorac Cardiovasc Surg 1997;114:738-45.

7. Monuszko E, Halevy S, Freese KJ, Shih HJ, Parikh NS, Jelveh Z, et al. Umbilical vessels endothelium and vascular reactivity. Microcirc Endothelium Lymphatics1990;6:183-208.

8. Chaudhuri G, Buga GM, Gold ME, Wood KS, Ignarro LJ. Characterization and actions of human umbilical endothelium derived relaxing factor. Br J Pharmacol 1991;102:331-6.

9. Chang JK, Roman C, Heymann MA. Effect of endotheliumderived relaxing factor inhibition on the umbilical-placental circulation in fetal lambs in utero. Am J Obstet Gynecol 1992;166: 727-34.

10. Myatt L, Brewer AS, Langdon G, Brockman DE. Attenuation of the vasoconstrictor effects of thromboxane and endothelin by nitric oxide in the fetal-placental circulation. Am J Obstet Gynecol 1992;166:224-30.

11. Wilkes BM, Mento PF, Hollander AM, Maita ME, Sung S, Girardi EP. Endothelin receptors in human placenta: relationship to vascular resistance and thromboxane release. Am J Physiol 1990;258:E864-70.

12. Myatt L, Langdon G, Brewer AS, Brockman DE. The comparative effects of big endothelin-1, endothelin-1, and endothelin-3 in the human fetal-placental circulation. Am J Obstet Gynecol 1992; 167:1651-6.

13. MacLean MR, Templeton AG, McGrath JC. The influence of endothelin-1 on human foeto-placental blood vessels: a comparison with 5-hydroxytryptamine. Br J Pharmacol 1992;106:937-41.

14. Reddy VM, Liddicoat JR, Klein JR, McElhinney DB, Wampler RK, Hanley FL. Fetal cardiac bypass using an in-line axial flow pump to minimize extracorporeal surface and avoid priming volume. Ann Thorac Surg 1996;62:393-400.

15. Cody WL, Doherty AM, He JX, DePue PL, Waite LA, Topliss J, et al. The rational design of a highly potent combined ETa and ETb receptor antagonist (PD 145065) and related analogs. Med Chem Res 1993;3:154-62.

16. Reddy VM, Hendricks-Munoz KD, Rajasinghe HA, Petrossian E, Hanley FL, Fineman JR. Post-cardiopulmonary bypass pulmonary hypertension in lambs with increased pulmonary blood flow: a role for endothelin 1. Circulation 1997;95:1054-61.

17. Wong J, Reddy VM, Hendricks-Munoz K, Liddicoat JR, Gerrets $\mathrm{R}$, Fineman JR. Altered endothelin-1 vasoactive responses in lambs with pulmonary hypertension and increased pulmonary blood flow. Am J Physiol 1995;269:H1965-72.

18. Westaby S. Organ dysfunction after cardiopulmonary bypass: a systemic inflammatory reaction induced by the extracorporeal circuit. Intensive Care Med 1987;13:89-95.

19. Komai H, Adatia IT, Elliott MJ, de Leval MR, Hawarth S. Increased plasma levels of endothelin-1 after cardiopulmonary bypass in patients with pulmonary hypertension and congenital heart disease. J Thorac Cardiovasc Surg 1993;106:473-8.

20. Jones DK, Luddington R, Higenbottam TW, Scott J, Cavarocchi $\mathrm{N}$, Reardon D, et al. Changes in factor VIII proteins after cardiopulmonary bypass in man suggest endothelial damage. Thromb Haemost 1988;60:199-204.

21. La M, Reid JJ. Endothelin-1 and the regulation of vascular tone. Clin Exp Pharmacol Physiol 1995;22:315-23.

22. Rutherford RA, Wharton J, McCarthy A, Gordon L, Sullivan MH, Elder MG, et al. Differential localization of endothelin $\mathrm{ET}_{\mathrm{A}}$ and $\mathrm{ET}_{\mathrm{B}}$ binding sites in human placenta. Br J Pharmacol 1993;109:544-52. 
23. Lüscher TF, Yang Z, Tschudi M, von Segesser L, Stulz P, Boulanger $\mathrm{C}$, et al. Interaction between endothelin-1 and endothelium-derived relaxing factor in human arteries and veins. Circ Res 1990;66:1088-94.

\section{Discussion}

Dr Edward D. Verrier (Seattle, Wash). In the past your group has shown that indomethacin impairs prostaglandins, and prostaglandins were previously postulated as the primary mechanism of these changes in PVR. How do the 2 stories work together? If you administer indomethacin, is that additive with the endothelin effects?

The second corollary question is about the relationship between nitric oxide and endothelin. Have you done studies that would do things to enhance nitric oxide synthase to maintain the vasodilatory response? What is the relationship between that and endothelin?

Dr McElhinney. One of the big questions that we are trying to get at now is the relationship among the various factors involved in postbypass placental dysfunction. We have found a number of factors that are associated with worse outcome and also a number of interventions that can lead to improved outcome. One of the main objectives that we are currently pursuing is trying to rationalize all these different mechanisms into a single model and determine what sort of interventions can result in optimal improvement. In response to your question, we do not really know how the endothelial and prostaglandin systems interact, although we are fairly certain that they are independent to some degree in this model.

With respect to your second question regarding the interaction between nitric oxide and ET-1, last year Champsaur and associates presented the results of an experiment in which they looked at the effects of pulsatile flow on nitric oxide activity in a fetal cardiac bypass model. They showed that pulsatile perfusion does in fact lead to improved placental hemodynamics, most likely as a result of stimulation of nitric oxide synthase. We know that nitric oxide normally antagonizes ET-1 in the fetoplacental circulation, and we also know that ET-1 acts differently according to the type of receptor on which it is working. There are $\mathrm{ET}_{\mathrm{A}}$ and $\mathrm{ET}_{\mathrm{B}}$ receptor subtypes that are located on both endothelial and smooth muscle cells, have differing affinities for ET-1, and exert both vasoconstrictive and vasodilatory effects according to where they are located. We used a nonspecific receptor blocker that blocks both $\mathrm{ET}_{\mathrm{A}}$ and $\mathrm{ET}_{\mathrm{B}}$ receptor subtypes and thus probably exerted its effects through multiple mechanisms. That is another area that we are trying to work out further.

Dr Renato Assad (Sao Paulo, Brazil). I have some concerns regarding pulmonary vascular resistance during fetal cardiac bypass. We know that pulmonary blood flow to the fetal lungs is about $8 \%$ of fetal cardiac output. During fetal cardiac bypass there is a shift of blood away from the placenta toward the lung. I have 2 questions regarding pulmonary blood flow and placental function during fetal cardiac bypass. First, did you measure pulmonary blood flow in this protocol? Second, did you assess placental function during and after fetal cardiac bypass, with and without the ET-1 receptor blocker?

Dr McElhinney. We did not measure pulmonary blood flow directly. We measured combined ventricular output with a perivascular flow probe on the ascending aorta summated with pump flow during bypass. After bypass we had a perivascular flow probe on the main pulmonary artery. If you are asking about placental function in terms of oxygenation and acid-base status, we did assess this. Oxygenation and acid-base status paralleled placental hemodynamics.

Dr Frank W. Sellke (Boston, Mass). Altered endothelial function after bypass has been demonstrated by many different groups. You have nicely extended this to the fetal circulation. I think the most interesting aspect of this work is the markedly hypercontractile effect in response to ET-1, which does not appear to me to be due to altered basal release of nitric oxide. The response simply seems to be too profound for that. To my way of thinking, it has to be some other alteration in another pathway, for example the cyclo-oxygenase pathway. The inducible cyclo-oxygenase level can be rapidly upwardly regulated and induced. You can see fairly marked increases in messenger RNA in relatively short periods after such pathologic interventions as bypass and ischemia. Furthermore, ET-1 is known to cause the release of nitric oxide. Do you think there may be some relationship there?

Dr McElhinney. Yes, I do think that there probably is a relationship between the nitric oxide and cyclo-oxygenase systems, and that is among the questions that we are hoping to answer. It has been shown in the past, by Dr Hanley and his group, that inhibition of the cyclo-oxygenase pathway markedly improves postbypass placental function. As I said earlier, one of the issues on which we are focusing now is trying to understand how these different systems interact and whether there is a final common pathway or they are parallel systems that are exerting separate effects.

With respect to the effect of ET-1, the placental circulation is thought to be maximally dilated in its basal state. Thus the addition of nitric oxide or any other vasodilator to the placental circulation in a nonconstricted state does not result in much vasodilation. This is an important consideration in looking at the vasoconstrictor response to ET-1 in this case. I do not have a good answer to your questions at this point, but you have pinpointed an important direction in which we hope to take our work. 